\title{
CONTRIBUTO PARA A DEFINIÇÃO DO REGIME JURIDICO APLICÁVEL AOS CONTRATOS DE GESTÃO PACTUADOS COM AS ORGANIZAÇÓES SOCIAIS
}

\author{
RODRIGO BORNHOLDT ${ }^{*}$
}

SUMÁRIO: 1. Introdução 2. A diferenciaçâo entre convênios e contratos 3. Dos contratos de gestão 4. Características 5. Conclusão.

\section{INTRODUÇÃO}

Na segunda metade do Século XX passou-se a, crescentemente, utilizar os contratos em substituição às imposiçōes unilaterais até entāo perpetradas pelo Estado. Os contratos administrativos, que surgiram como exceçāo, tornaram-se praticamente a regra.'

Dentre desse contexto, assiste-se à introduçāo, no direito brasileiro, da figura do contrato de gestāo, no âmbito das organizaçōes sociais ${ }^{2}$, o que traz uma série de questionamentos à doutrina administrativista. Para que a natureza

* Mestrando da Faculdade de Direito da UFPR. Procurador-Geral do Município de Joinville - SC.

' Importa aqui considerar as advertências de Enzo Roppo, no sentido de que, se isto por um lado é positivo, na medida em que fortalece a possibilidade de participaçāo dos particulares, por outro deve ser cercado de cautelas, a fim de que sejam evitadas colusóes capazes de conduzir à malversação de dinheiro público. O Contrato, p.346.

${ }^{2}$ Năo se pode olvidar a polissemia da expressăo "contratos de gestāo". Há consequiências jurídicas diversas entre o contrato de gestăo com escopo de lucro do particular, e o contrato de gestăo no âtnbito das Organizaçōes Sociais, sem intuito de lucro. Aqueles seriam, inclusive, ilegais. Cfr. Marçal Justen Filho, Concessōes de serviços públicos. p. 109-110. 
jurídica desse tipo de contrato possa aflorar, é necessário um aprofundado cstudo acerca da diferenciação entre convênios e contratos administrativos. Em seguida, busca-se descobrir quais as conseqüências que podem advir da responsabilidade estatal, no caso de rompimento do contrato. Por fim, estudamse algumas características próprias do instituto.

Para que a análise tenha êxito, pretende-se utilizar as construçōes já feitas pela teoria, sem, contudo, deturpar a novidade e as peculiaridades desse novo contrato. A teoria deve compreender a realidade, e não deturpá-la. Assim, as construções até aqui existentes são insuficientes para abarcar a complexidade da nova figura. Para que ela ganhe consistência, é necessário que se abandone também o liberalismo possessivo ${ }^{3}$, implícito à maioria de nossa doutrina, fazendo com que, nos contratos, seja protegida una dimensão maior que a puramente econômica. ${ }^{4}$

\section{A DIFERENCIAÇÃO ENTRE CONVÊNIOS E CONTRATOS}

O contrato de gestāo é uma figura jurídica que se confunde ora com os contratos administrativos, ora com os chamados convênios, firmados entre pessoas jurídicas de direito público, ou entre órgãos do Estado e particulares. ${ }^{5}$ Para que se tenha uma concepção mais apurada de sua natureza, importa sejam diferenciados os referidos institutos.

Uma das detiniçōes da doutrina tradicıonal considera a diferença entre contratos administrativos e convênios a partir da natureza das partes envolvidas.

${ }^{3} \mathrm{O}$ tema ć tratado com profundidade e grandeza por C. B. Mcpherson, Ascensāo e queda da justiģa econômica e outros ensaios, p.115-122.

${ }^{4}$ No direito administrativo brasileiro, o tema é versado por Juarez Freitas, Estudos de direito administrativo, p.180. Assim, o presente trabalho pressupóes a distinçäo entre princípios e regras. Os princípios possuem densidade menor e abertura maior que as regras, que săo completas. Por isso, as regras ou se compatibilizam, se acoplam umas às ouiras, ou sāo incompatíveis. Já os princípios permitem ponderaçóes entre eles em casos de conflito. Dado seu caráter fundante, os princípios irradiam-se por todo o sistema jurídico, ao contrário das regras.

${ }^{5}$ Admitindo os convênios entre Estado e particulares, Maria Sylvia Zanella di Pietro, Parcerias na Administraçāo Priblica, p.112. Referindo-se aos convênios apenas como ajuste entre pessoas jurídicas de direito público, Marçal Justen Filho, Comentários à Lei de Licitą̧ōes e Contratos Administrativos, p.524; Carlos Ari Sundfeld, Licitą̧áo e contrato administrativo, p. 198; Manoel Oliveira Franco Sobrinho, Contratos administrativos, p.248. 
Os convênios seriam firmados apenas entre pessoas jurídicas de direito público. ${ }^{6}$ Tal distinção é duplamente errônea: nāo apenas contratos podem ser realizados exclusivamente entre pessoas jurídicas de direito público, mas também os convênios podem ser realizados, sendo uma das partes uma pessoa de direito privado.

Uma segunda distinção, igualmentc tradicional e importante, apresenta o convênio como instituto caracterizado por visar à confluência dos interesses das partes, que caminhariam numa direçāo, enquanto o contrato seria uma resultante de interesses contrapostos. ${ }^{7}$

Outra distinção relevante entre convênios e contratos é dada por Maria Sylvia Zanella di Pietro, asseverando que, no convênio, é necessário sempre um acompanhamento pari pussu da destinação dos recursos estatais, enquanto que, no contrato, basta demonstrar o resultado final do desempenho da atribuiçāo ajustada para que o montante recebido pelo particular não se sujeite ao controle público. ${ }^{8}$

Conquanto relevantes as duas últimas distinçōes, pensamos não atingirem ela o âmago da distinçāo entre os institutos, pelas seguintes razōes: a) doutrinariamente, os convênios podem igualmente ser considerados contratos, ainda que de tipo diverso dos tradicionais, consistentes nos comutativos; b) nāo logram estabelecer uma diferença de regime jurídico entre ambos os institutos, fator essencial para qualquer justificável distinção.

No que concerne ao primeiro ponto, afirma Marçal Justen Filho que também os convênios? podem ser tidos como contratos. Uma possível divisão entre eles, na esteira do direito privado, os classifica em comutativos e cooperativos. Estes últimos seguem a noçāo proposta por Ascarelli, diferenciando-se dos primeiros pelo escopo das partes, que é o mesmo. Não obstante, também aqui encontram-se direitos e deveres estipulados, enquanto meios para a consecução das finalidades propostas.

Para a aceitação desse postulado, importa a análise dos elementos essenciais caracterizadores de qualquer contrato.

${ }^{6}$ Apresentado por Marçal Justen Filho, Comentários..., p.524.

${ }^{7}$ Hely Lopes Meirelles, Direito Administrativo Brasileiro, 358; Maria Sylvia Zanella di Pietro, op. cit., p.112-112, ainda que adicionando outras diferenças.

${ }^{\circ}$ Maria Sylvia Zanella di Pietro, op. cit., p.116.

'Ainda que esse autor os refira sempre ao acordo realizado entre sujeitos de direito público interno. Comentários..., p.524. 


\section{É Marçal Justen Filho quem fornece esses traços decisivos. A diferença} entre atos e contratos residiria na possibilidade de, a par de se reconhecer efeitos jurídicos a uma vontade exteriorizada (o que ocorre também no ato), as partes estabelecerem um estatuto normativo, criando autonomamente uma disciplina jurídica vinculante. ${ }^{10}$ Esse seria um requisito essencial para todo e qualquer contrato, administrativo ou nāo. Sua característica própria de contrato administrativo se revelaria posteriormente, face à existência ou nāo das chamadas cláusulas exorbitantes", prerrogativa da Administraçāo Pública que, por outro lado, ao desempenhar funçāo ${ }^{12}$, nāo é possuidora de autonomia da vontade (própria aos contratos pariiculares). Em todo caso, administrativo ou nāo, todo verdadeiro contrato vincula as partes, a partir de uma disciplina estabelecida autonomamente.

Parece inegável que os convênios possuem esses traços essenciais que reclamar os contratos, podendo ser enquadrado como uma de suas espécies. Com efeito, as partes que o celebram estabelecem um disciplina jurídica que lhes é vinculante, consistente em direitos e deveres.

Se há, contudo, algum fator que justificaria a diferenciaçāo entre as espécies dos contratos tradicionais e dos convênios, este residiria num regime jurídico diverso aplicável a cada um deles.

Assim, a doutrina e a jurisprudência parecem reconhecer um critério diferencial, capaz de justificar as distintas figuras: os convênios seriam passíveis

"Marcal Justen Filho divide o contrato cm contrato-ato e centrato-relação. Concessōes..., p.2325. A definiçăo pode ser complementada, quanto aos contratos administrativos, pela lição de Sérvulo Correia, que, ao distinguir os contratos administrativos dos atos administrativos dependentes de colaboraçáo do administrado, entende cono determinante a análise da estruturà do ato. Sé a vontade do particular é requisito de existência, está-se perante um contrato. Se constituir um requisito de legalidade ou de eficácia, estar-se-á perante um ato administrativo. José Manuel Sérvulo Correia, Legalidade e autonomia contratual nos contratos administrativos, p.350.

"A expressāo é reconhecidamente imprópria e ultrapassada, conforme atesta nossa doutrina, através, especialmente, de Marçal Justen Filho, Concessōes...; e Juarez Freitas, Estudos... Sérvulo Correia, muito a propósito, afirma que o critério das cláusulas exorbitantes é útil na medida em que refletem a busca de um critério de fundo, que consistiria na própria especificidade do Direito Administrativo, determinada por um critério estatutário. Nesse sentido, o contrâto administrativo è um contrato que "constitui um processo próprio de agir da Administraçāo pública e que cria, modifica ou extingue relaçōes jurídicas, disciplinadas em termos específicos do sujeito administrativo, entre pessoas coletivas da Administraçāo ou entre a Administraçāo e os particulares." Ainda segundo o autor, isso não significa a total autonomia do contrato administrativo com relaçăo ao contrato em geral. Op. cit., p.362-396.

12 Marçal Justen Filho, Concessōes..., e Celso Antonio Bandeira de Mello, Curso de direito administrativo, p.29. 
de denúncia a qualquer tempo. ${ }^{13}$ Ainda que versando acerca dos convênios stricto sensu, firmados entre órgāos públicos, a tendência parece se estender também para os convênios celebrados com os particulares. ${ }^{14}$

O fato de os convênios poderem ser denunciados a qualquer tempo nāo significa a inexistência de uma disciplina vinculante, o que os descaracterizaria enquanto contratos. A denúncia gera, via de regra, efeitos ex nunc, sendo devidas as prestaçōes anteriores. ${ }^{15}$ Para que se opere, porém, é necessário seja ela motivada. ${ }^{16}$ Nesse momento, dispōe a Administração Pública de uma amplíssima margem de discricionariedade ${ }^{17}$, a qual, contudo, nāo poderá ser exacerbada, sob pena de desencadeamento da responsabilidade ${ }^{18}$ estatal.

É exatamente neste ponto que ocorre uma diferença fundamental entre os convênios e os tradicionais contratos administrativos ${ }^{19}$ : a margem de

${ }^{17}$ Hely Lopes Meirelles, Direito Administrativo Brasileiro, p.354 e ss.

${ }^{14}$ Maria Sylvia Zanclla di Pietro, op. cit., p.112.

${ }^{15}$ Contra: Edmir Netto de Araújo, Do negócio juridico administrativo, p. 146, apud Maria Sylvia Zanella di Pietro, op. cit., p.113. Segundo esse autor, haveria ausência de vinculaçäo contratual", inexistindo “[...] sançōes pela inadimplência [...]". Há aqui um conflito entre princípios: de um lado, o princípio da unidade do poder público; de outro, o já mencionado princípio democrático, a impedir que a ação de um novo governante seja tolhida pelo engessamento provocado pelo anterior. Ambos devem reciprocamente ceder, sendo a decisão construída pelo magistrado. Sobre o conflito entre princípios, Eros Roberto Grau, $A$ ordem econômica na Constituiçăo de 1988, p.46 e ss. No mesmo sentido da vinculaçăo provocada pelo convênio parece se posicionar Marçal Justen Filho, para quem "nāo se pode entender o convénio como ato juridicamente irrelevante, cujas conseqüencias poderiam ser ignoradas a qualquer tempo. Os deveres e obrigaçōes assumidos pelas pessoas políticas săo juridicamente válidos e devem ser observados e respeitados. Mas o descumprimento a tais compromissos se resolverá na sede adequada, compatível com a natureza do princípio federativo." Concessōes..., p.77.

1h A aceitaçăn de atos arbitrários parece reconhecida apenas pela vetusta teoria dos atos de governo. Jean Rivero, Direito Administrativo, p. 345. Arualmente, é praticamente unânime a existência de motivação dos atos administrativos por parte da doutrina. Cfr., por todos, Juarez Freitas, O conitrole dos atos adminitistrativo $e$ os princípios fundamentais, p.41-44. Entende-se ser o princípio extensivo também à denúncia.

${ }^{17} \mathrm{O}$ conceito de discricionariedade aqui adotado advém de Castanheira Neves, O problema da discricionariedade, in Digesta, Vol. I, p.551 e ss. Para o autor, a tentativa de sc considerar os juízos discricionários como juízos desvinculados do Direito e da ordem jurídica cristalizam o fracasso do modelo metodológico teorético-subsuntivo. A discricionariedade nāo pode ser tratada como uma categoria autônoma na metodologia da aplicaçăo do Direito. Sua correta compreensāo passa pelo reconhecimento do quanto há de autonomia de juízo e de decisão no domínio dito de subsunçāo, e do quanto há de vinculaçāo no

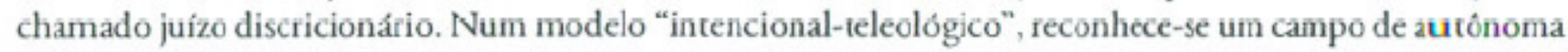
avaliaçāo do julgador, nāo se confundindo a necessidade de considerar a conformaçăo especial do caso concreto com uma pura discricionariedade, alheia ao Direito.

${ }^{18}$ A responsabilidade deve ser entendida num sentido estrito, enquanto compensação pelo rompimento, e nāo apenas pela indenizaçāo ou execuçāo de valores anteriormente devidos.

${ }^{10}$ Uma diferença, contudo, de grau e não de gênero, o que permite sejam ambos considerados contratos administrativos. 
discricionariedade outorgada ao administrador para o rompimento de um contrato administrativo propriamente dito é sensivelmente menor. Ademais, por vezes, mesmo que não ultrapassada essa margem, haverá o desencadeamento da responsabilidade estatal, pois admitida aqui a responsabilidade por fato lícito, o que nāo ocorre nos convênios. ${ }^{20}$

Portanto, a melhor distinção entre convênios e contratos, a par da questão da confluência ou contraposiçāo de interesses, é aquela consistente em dois aspectos: a) a variada margem de discricionariedade para uma lícita ruptura: de quase absoluta nos convênios entre pessoas jurídicas de direito público, para bastante restrita nos contratos; b) a impossibilidade de desencadeamento de responsabilidade por fato lícito, no caso dos convênios.

\section{DOS CONTRATOS DE GESTÃO}

Assentes as diferenças entre os convênios e os contratos administrativos em geral, cabe situar o contrato de gestāo dentro desse contexto. ${ }^{21}$

Situa-se numa categoria intermediária entre os convênios firmados por órgāos públicos e os contratos administrativos, a partir do critério diferencial proposto.

Aproximam-se dos tradicionais contratos administrativos por possuírem uma menor margem de discricionariedade para o rompimento lícito do ajuste. Por outro lado, além de ser firmado visando a um escopo comum, tem em comum a categoria ćos convênios o fatu de nāu admitir a iesponsábilidade por fato lícito.

Tanto uma interpretação sistemática quanto teleológica justificam as assertivas. Ao prever a estipulação detalhada de diversos direitos e deveres entre as partes $^{22}$, a lei pretende conferir uma pretensão de longevidade ao instrumento.

so É que, no campo dos contratos administrativos, um rompimento unilateral, sem culpa do contratado, poderá acarretar a responsabilidade administrativa, ainda que o ato seja lícito. $\hat{E}$ a hipótese prevista no inc. XII do art. 78 de Lei de Licitaçōes. No caso de licitude do sompimento, porém, o particular năo poderia pleitear a execução do contrato até seu final.

${ }^{21}$ Nảo se aprofundará, neste trabalho, a temática dos convênios entre pessoas públicas e privadas, bastando, contudo, assinalar o parentesco entre estes e os contratos de gestão firmados com as organizaçōes sociais, conforme ensina Paulo Modesto, Reforma Administrativa e marco legal das organizạ̧ōes sociais no Brasil, p.6. Por outro lado, parcecm estar mais próximas dos tradicionais convênios, no que concerne à discricionariedade conferida para um rompimento unilateral.

${ }^{22}$ Conforme incisos I e II do art. $7^{\circ}$ da Lei n. ${ }^{\circ} 9637 / 88$. 
Mais que isso, o próprio objetivo da administraçāo gerencial prevê a fixaçāo e alcance de determinados resultados, que somente serāo alcançados decorrido um certo tempo. O legislador procurou conferir maior liberdade ao gestor em troca do alcance de determinados resultados, que necessariamente dependem do fator tempo.

Assentadas essas definiçóes, questionamento importante poderia surgir, no que concerne à validade de eventual cláusula prevendo a possibilidade de denúncia unilateral do contrato, sem culpa da parte contrária. Em princípio, pelas razōes expostas, deveria ser adotada a analogia com o inc. XII do art. 78 de Lei de Licitaçōes. É uma vez mais uma interpretaçāo teleológica, consciente da diferenciação entre princípios e regras, que fornece a justificativa para a soluçāo. Se pretende ser um instrumento de promoçāo da cidadania, nāo poderia o rompimento ser realizado a qualquer tempo, sem razăo aparente. Cidadania significa a possibilidade de intensa participaçāo popular "na gestāo dos negócios da cidade" 23 , requerendo, do lado governamental, o cumprimento de princípios previstos constitucionalmente, tais como a proteçāo da confiança, da boa fé e do interesse público objetivamente considerado, calcado, in casu, na estipulação e cumprimento de indicadores objetivos constantes dos contratos de gestāo.

Isso nāo significa a simultânea aplicabilidade da regra contida no $\$ 2^{\circ}$ do art. 79 da Lei 8666/93, visto que a organização social nāo desempenha atividade econômica, e, portanto, não visa ao lucro. Assim, não haverá a responsabilidade da Administraçāo por ruptura lícita. É apenas nos casos de uma ruptura ilícita, mensurada pelos critérios fornecidos pelo inc. XII do art. 78 da icfirida lei, que o contratado fará jus a uma compenseŗān.

Essa, contudo, terá por base nāo um prejuízo econômico, mas uma ofensa moral à organização social. Ao invés de um núcleo intangível do princípio do equilíbrio econômico-financeiro, característico da proteçāo oferecida ao particular nos contratos administrativos, poder-se-ia aludir a uma espécie de núcleo de proteçāo moral da Organizaçāo Social. Nāo é pelo fato de nāo buscar a lucratividade que a reputação da Organizaçāo Social deva estar além da protcção ofcrtada pelo Direito.

Eventuais sançōes aplicáveis devem, pois, se sujeitar ao atendimento desses princípios.

${ }^{23}$ BARACHO, José Alfredo de Oliveira. Teoria Geral da Cidadania, p.3. 


\section{CARACTERÍSTICAS}

Não se encontram nos contratos de gestão as características próprias dos contratos administrativos tradicionais, consistentes, basicamente, na intangibilidade da equaçāo econômico-financeira; no direito ao objeto contratual inalterável estruturalmente, e no recebimento do preço avençado. ${ }^{24}$ Ao invés, como afirmado, haveria, como princípio alternativo ao do equilíbrio econômico-financeiro, uma espécie de reserva moral do particular ${ }^{25}$, a ser respeitada pelo Estado.

Importa, contudo, evitar os graves riscos de colusāo que podem advir da realizaçāo de contratos no âmbito da Administraçāo Pública. Para tanto, é necessário que a sociedade possua mecanismos objetivos de avaliação dos itens do acordo firmado, em especial para avaliação do programa de trabalho e das metas a serem atingidas, previstas no inc. I do art. $7^{\circ}$ da Lei no 9637/98. Tal exigência é imposta pelos princípios da publicidade e da moralidade. Nāo obstante, esses controles possuem limites. Assim, é evidente que organizaçōes não governamentais, o Ministério Público ou mesmo o Poder Judiciário, não poderāo determinar quantitativos absolutos dos pactos firmados, pois neste caso substituiriam atividades próprias do Executivo e das Organizaçōes Sociais, mas podem, isto sim, manifestar-se quanto à razoabilidade dos acordos firmados. Em outras palavras, permanecerá uma margem de discricionariedade própria da atividade executiva, mas em nenhum momento poderāo ser aceitos pactos que venham a fragrantemente deturpar os objetivos da gestāo. ${ }^{26}$

Já as cláusulas exorbitantes (existentes ex lege), consistiriam na possibilidade de alteração das metas a serem atingidas e dos prazos de execuçāo, na possibilidade de estreita fiscalização e na rescisão.

Tanto os contratos administrativos como os de gestão são realizados intuitu personae. Varia, contudo, o modo de escolha. No primeiro, adstringe-

${ }^{24}$ FIGUEIREDO, Lucia Valle. Contratos administrativos, in Direito administrativo na Constituiçāo de 1988 , p.149.

${ }^{25}$ Que parece ser traduzida também pelo disposto no $\$ 10$ do art. 16 da Lei $9637 / 98$, pois, ainda que versando sobre desqualificaçăo, reconhece a imagem a ser preservada pela instituiçăo.

${ }^{26}$ Assim, por exemplo, se, na área da educaçāo, foram criadas 100 escolas com R\$ 3.000.000,00, cm um ano, nāo será admissível que um contrato de gestão preveja, com o mesmo dinheiro a ser gasto, um número menor de escolas de igual padrāo a serem construídas. O princípio da eficiência cstaria sendo flagrantemente desrespeitado, bem como o da economicidade. 
se ela aos requisitos das leis de licitaçōes. No segundo, dás-se de acordo com a conveniência e confiança da Administração. ${ }^{27}$

No contrato de gestão, é conferida maior liberdade ao contratado; sua contrapartida é, contudo, associada à maior eficiência. Sua adoçāo no direito brasileiro auxilia a concretizaçāo do princípio da economicidade e eficiência, inscritos, respectivamente, no caput dos arts. $70^{28}$ e 37 da Constituição Federal.

\section{CONCLUSŌES}

Do exposto, pode-se concluir:

a) o critério para existência de todo contrato, administrativo ou não, consiste na possibilidade do estabelecimento de uma disciplina vinculante para as partes;

b) os convênios podem ser considerados um tipo de contrato administrativo - cooperativo -, distinto dos tradicionais contratos comulativos;

c) nenhum dos critérios tradicionalmente propostos pela doutrina para a distinção entre convênios c contratos - diversas partes; confluência ou contraposiçāo de interesses - é suficiente para abarcar a diversidade de seu regime jurídico;

2" Entende-se cumo pusivel a iealizaçüo de !ieitaçăo. A escollha política do legielarìor, porém, nāo deve ser descartada como ilegal ou inconstitucional, sob pena de desrespeito ao princípio democrático, que parece permitir à Administraçāo escolher com quem pretende contratar num típico contrato de cooperaçăo. Tanto essa situaçāo, como a nomeaçāo de cargos em comissāo, seriam exceçōes constitucionalmente toleradas au princípio da impessoalidade da Administraçăo Pública. A segunda delas, por expressa previsāo constitucional, a primcira, pela delegaçāo do inc. XXI do art. 37 da Constituiçăo à legislação infraconstitucional. Admita-se, contudo, que é discutível uma tal amplitude à exceçāo. Outro ponto a ser analisado consistiria na necessidade de que nāo fosse ultrapassado o mandato do agente político que celebra o contrato de gestão, sob pena de burla ao princípio democrático. Ou melhor, que o prazo estipulado apenas ultrapassaria o mandato na medida $\mathrm{em}$ que fosse ratificado pelo novo titular de mandato eletivo. Isto em decorrènciá, como visto, dō princípio democrático. Se o podêr èmana do povoo, è em seu nomé é exercido por representantes legitimamente eleitos, năo cabe, ainda que sob o pretexto da fixação de resultados, ou do êxito anterior, restringir sua livre atividade discricionária no âmbito da prestaçāo de serviços públicos relativos a pontos política e socialmente sensíveis, tais como saúde e educação. Se um serviço vinha sendo desempenhado com êxito, e deixou de sê-lo, cabe o repúdio político ao governante que permitiu um tal estado de coisas.

${ }^{28}$ Cfr. Juarez Freitas, $O$ controle..., p.85. Alguns o associavam ao princípio da economicidade, constante do caput do art. 70 da Constituição Federal. 
d) a diferença entre convênios e contratos é unicamente de grau, e não de gênero, consistindo, de um lado, na ampla margem de discricionariedade outorgada ao administrador para um rompimento unilateral; e, de outro, na inexistência, no âmbito do convênio, da responsabilidade por fato lícito;

e) os contratos de gestão situam-se numa zona intermediária entre os convênios e os contratos administrativos propriamente ditos, aproximando-se destes pela pequena margem de discricionariedade outorgada, para um lícito rompimento; e daqueles, pela inexistência, em seu âmbito, da responsabilidade por fato lícito;

f) no âmbito do contrato de gestāo, a responsabilidade surgirá pela necessidade de proteçāo moral à organizaçāo social;

g) os contratos de gestão caracterizam-se por serem realizados intuitu personae, por possuírem um núcleo de reserva moral do contratado, por privilegiar os fins sobre os meios, por nāo possuírem intuito lucrativo e por não acarretarem riscos financeiros ao contratado.

\section{REFERÊNCIAS BIBLIOGRÁFICAS}

BANDEIRA DE MELLO, Celso Antonio. Curso de direito administrativo. $7^{\text {a }}$ Ed., São Paulo: Malheiros Ed., 1995.

BARACHO, José Alfredo de Oliveira. Teoria Geral da Cidadania. São Paulo: Saraíva, 1995.

CASTANHEIRA NEVES, A. O problema da discricionariedade, in Digesta, Vol. I. Coimbra: Coimbra Editora, 1995.

FIGUEIREDO, Lucia Valle. Contratos administrativos, in Direito administrativo na Constituiçāo de 1988. São Paulo: Revista dos Tribunais, 1991.

FRANCO SOBRINHO, Manoel Oliveira. Contratos administrativos. Sāo Paulo: Saraiva, 1981.

FREITAS, Juarez Freitas. O controle dos atos administrativos e os princípios fundamentais. São Paulo: Malheiros, 1997. 
Estudos de direito administrativo, São Paulo: Malheiros Ed., 1995.

GRAU, Eros Roberto. A ordem econômica na Constituição de 1988. 2a Ed., São Paulo: Revista dos Tribunais, 1991.

JUSTEN FILHO, Marçal. Concessōes de serviços públicos. São Paulo: Dialética, 1997.

Comentários à Lei de Licitaçôes e Contratos Administrativos. $4^{\mathrm{a}}$ Ed., Rio de Janeiro: AIDE, 1997.

McPHERSON, Crawford Brough. Ascensão e queda da justiça econômica e outros ensaios. Rio de Janeiro: Paz e Terra, 1991.

MEIRELLES, Hely Lopes. Direito Administrativo Brasileiro. 18 ${ }^{a}$ Ed., São Paulo: Malheiros Ed., 1993.

MODESTO, Paulo. Reforma Administrativa. Coimbra: Almedina, 1981.

ROPPO, Enzo. O Contrato. Coimbra: Almedina, 1988.

SÉRVULA CORREIA, José Manuel. Legalidade e autonomia contratual nos contratos administrativos. Coimbra: Almedina, 1987.

SUNDFELD, Carlos Ari. Licitaçáo e contrato administrativo. São Paulo: Malheiros Ed., 1994.

ZANELlA DI PIETRO, Maria Sylvia. Parcerias na Administraçāo Pública. Sāo Paulo: Atlas, 1996. 